\title{
Echocardiography assessment of the left ventricle apical morphology and dynamics in patients with unexplainable deep T-wave inversion and apical wall thickness $<15 \mathrm{~mm}$
}

\section{Shengnan Lin}

First Affiliated Hospital of Fujian Medical University

Qinyun Ruan ( $\sim$ qyruan@126.com )

First Affiliated Hospital of Fujian Medical University

Chunyan Huang

First Affiliated Hospital of Fujian Medical University

Lei Yan

First Affiliated Hospital of Fujian Medical University

Liyun Fu

First Affiliated Hospital of Fujian Medical University

Huang'e Cai

First Affiliated Hospital of Fujian Medical University

\section{Research}

Keywords: apical angle, apical hypertrophic cardiomyopathy, velocity ratio

Posted Date: March 9th, 2020

DOI: https://doi.org/10.21203/rs.3.rs-16239/v1

License: (c) (i) This work is licensed under a Creative Commons Attribution 4.0 International License.

Read Full License 


\section{Abstract}

Background:

There exists a group of patients with the same ECG characteristics as typical apical hypertrophic cardiomyopathy (AHCM) but fails to reach the diagnostic criteria. The objective of this study was to evaluate the apical morphological and dynamical features of this type of patients using echocardiography.

Methods:

A total of 30 subjects with unexplainable T-wave inversion (TWI) on ECG and apical myocardium thickness $<15 \mathrm{~mm}$ by echocardiography were recruited. The apical morphological and dynamic features included the left ventricular (LV) apical-to-basal posterior wall thickness ratio (ABR), apical angle (apA) and its percentage change in cardiac cycle, peak blood flow velocity at the apical cavity (Vap) and its ratio to the velocity at LV outflow tract (Vap/VLVOT). The results were compared to those from 32 patients with typical AHCM, 44 with essential hypertension and 43 healthy controls.

Results:

Compared to healthy controls and hypertension patients, the suspected AHCM group had a significantly higher $A B R(1.37 \pm 0.23$ vs. $0.75 \pm 0.08$ and $0.75 \pm 0.11, P<0.001)$, lower apAs, higher percent change of apA ( $74 \pm 23 \%$ vs. $16 \pm 8 \%$ and $28 \pm 13 \%, P<0.001)$ and higher Vap/VLVOT ( $0.5 \pm 0.3$ vs. $0.3 \pm 0.1$ and $0.3 \pm 0.1$, $\mathrm{P}<0.05)$. Patients with typical $A H C M$ had similar apAs and its change and significantly higher $A B R$ $(1.85 \pm 0.42, P<0.001)$ and Vap/VLVOT $(0.8 \pm 0.5, p=0.009)$ than the suspected AHCM group.

Conclusion:

Apical morphology and dynamic features of subjects with TWI and LV apical thickness $<15 \mathrm{~mm}$ were significantly different from healthy controls and hypertension patients, but shared similarities with typical AHCM patients. The results suggest this suspected group may be in an early stage or exhibit a mild phenotype of AHCM. With careful assessment and additional quantitative measurements, it is possible to detect this suspected AHCM group using echocardiography.

\section{Introduction}

Apical hypertrophic cardiomyopathy (AHCM) is a variant of hypertrophic cardiomyopathy $(\mathrm{HCM})$ that exhibits an apical dominance and involves sarcomere protein gene mutations. AHCM is characterized by a spade-like configuration of the left ventricular (LV) cavity and symmetrical deep inverse T-waves in the $\mathrm{ECG}^{1,2}$. As established in the 2014 European Society of Cardiology guidelines ${ }^{3}$, the diagnosis of AHCM is defined as the maximal apical wall thickness (APWT $\max$ ) $\geq 15 \mathrm{~mm}$ at the LV end-diastole combined with abnormal ECG findings. However, there exists a group of patients who have similar abnormal ECG characteristics but only mild apical hypertrophy that does not meet the diagnostic criteria of AHCM. 
Studies using magnetic resonance imaging (MRI) suggested that this group represents a mild form of AHCM or an incomplete disease expression who may be considered as normal but at equal risk as typical $\mathrm{AHCM}^{4}$. Patients with this suspected type of AHCM have been found to have relatively thicker LV apex versus its basal, systolic apical cavity obliteration and a decreased apical angle by MRI ${ }^{4,5}$. Despite these findings, there are few echocardiographic reports by addressing this issue.

Routine echocardiographic exams are known to be weak when imaging the LV apex and result in many false negative interpretations ${ }^{6}$. Nevertheless, we believe with the increasing spatial and temporal resolutions, the current techniques by echocardiography allows us to appreciate LV apex in a better way. Therefore, the aim of the current study was to investigate the apical morphological and dynamic characteristics in suspected AHCM patients using echocardiography, and to compare the findings to typical AHCM patients, healthy subjects and patients with hypertension. We assumed that the suspected AHCM patients had abnormal LV apical morphology and dynamics by echocardiography, which can help to early diagnose this group.

\section{Methods}

\section{Study population}

Two patient groups who visited our echo lab from August 2015 to August 2018 were retrospectively selected to participate in this study. The suspected AHCM group exhibited a maximal apical wall thickness ( $A P W T_{\max }$ ) by echocardiography less than $15 \mathrm{~mm}$ but greater than the basal wall thickness, i.e. apex: base ratio $(A B R)>1$ (normal ABR range $0.85-0.90)^{4,7}$. Suspected AHCM patients had an unexplainable T-wave inversion ( $T W I \geq 5 \mathrm{~mm}$ ) on ECG, predominantly on the anterolateral leads (V3-V5 leads) without evidence of ischemic cardiomyopathy. No patient in this group had family history of HCM.

The typical AHCM group was diagnosed according to the following criteria: (1) deep T-wave inversion on ECG as the suspected group; (2) APWT $\max \geq 15 \mathrm{~mm}$ with an $A B R \geq 1.5$ as measured by echocardiography ${ }^{8}$; (3) no evidence of clinical or radiographic evidence of coronary artery disease or other structural heart diseases.

Forty-three healthy controls who volunteered for the current study were compared to suspected AHCM group. The healthy controls were carefully screened to ensure that none had a suspicious history of heart disease or relevant medical history. We also included a group of patients with essential hypertension (> $140 / 90 \mathrm{mmHg}$ ) who visited our lab during the same time period.

All subjects enrolled had a sinus rhythm with sufficient image quality to identify wall contours. ECG, transthoracic echocardiography and blood pressure measurements were obtained on the same day for each subject. The current study was approved by the Ethics Committee of the First Affiliated Hospital of Fujian Medical University . 


\section{Echocardiography Acquisition And Routine Image Analysis}

Comprehensive transthoracic echocardiography was performed in all subjects with a Siemens Sc2000 ultrasound system using a $4 \mathrm{~V} 1 \mathrm{C}$ transducer at the appropriate frequency. All subjects took the left lateral decubitus position with breath holding for three cardiac cycles when images were taken. Standard 2dimensional (2D) measurements were performed according to the recommendations of the American Society of Echocardiography ${ }^{9}$. LV ejection fraction (LVEF) was measured using the biplane method of disks (modified Simpson's rule) and the biplane left atrium volume (LAV) was obtained using the arealength method. The left atrium volume index (LAVI) was calculated as the LAV divided by the body surface area. Early diastolic mitral inflow velocity (E) and late diastolic mitral inflow velocity (A) were measured using the pulsed wave Doppler method by placing the sample volume at the level of the mitral valve leaflet tips. Tissue Doppler imaging (TDI) derived early diastolic mitral annular velocities at the basal lateral wall $\left(\mathrm{e}_{1}\right)$ and at the septum $\left(\mathrm{e}_{2}\right)$ were measured from the apical 4-chamber view.

\section{Assessment Of Apical Morphology And Dynamics By Echocardiography}

To assess apical hypertrophy, 2D image quality was optimized with the appropriate frequency according to subjects' body size (1.7-4.0 MHz). But whenever possible, probe with higher frequency was preferred. Harmonic imaging was always applied. Sector width and image depth were adjusted to maximize the special and temporal resolutions, but sufficient to include the whole LV. Maximizing the LV area and acquiring LV views at a reduced depth with focusing on LV cavity was attempted to reduce the likelihood of LV foreshortening. The maximum apical wall thickness was measured in the standard apical 4- and 2chamber views at end-diastole when the cardiac apex was clearly visible. For LV apical thickness, measurement was performed perpendicular to the axis of the wall at the point of maximal thickness. Trabeculae papillary muscles were carefully avoided. The apex-to-base ratio (ABR) was calculated as the ratio of the LV apical wall thickness to the LV posterior basal wall thickness. The systolic (apA-s) and diastolic (apA-d) apical angles were measured from the apical 4-chamber view at LV end-systole and enddiastole, respectively (Fig. 1). Papillary muscles and trabeculae were excluded when drawing the angle. The percentage change of the apical angle during the cardiac cycle was calculated according to Eq. 1.

$$
\frac{(a p A-d)-(a p A-s)}{(a p A-d)} * 100 \quad \text { Eq. } 1
$$

The peak blood flow velocities at the apex (Vap) and LV outflow tract $\left(\mathrm{V}_{\mathrm{LVOT}}\right)$ during systole were acquired from the apical five-chamber view using pulsed-wave Doppler (Fig. 2,3). Velocity values were averaged from three cardiac cycles. The velocity ratio was defined as the ratio of $V_{a p}$ to $V_{\mathrm{LVOT}}$ 


\section{Definitions Of Abnormal Ecg T Wave}

Routine 12-lead ECG was collected from all participants. Deep TWI was defined as a T-wave voltage $\geq$ $0.5 \mathrm{mV}$. A giant negative T-wave (GNT) was defined as a T-wave voltage $\geq 1.0 \mathrm{mV}$.

\section{Statistics}

All statistical analyses were performed using the SPSS 20.0 software. Categorical variables are expressed as numbers (proportion) and continuous variables are presented as the mean \pm standard deviation. Independent samples t-test was used to compare continuous data between two groups. A chisquared test was used to compare categorical data. A P value $<0.05$ was considered statistically significant. Intra- and inter-observer variability of morphological parameters and Vap were measured in 20 randomly selected subjects from each group. Images from these subjects were analyzed by two experienced operators who were blinded to the echocardiographic, ECG and clinical data, and repeatedly measured two months later. The results were assessed by mean \pm SD differences and intraclass correlation between observations (Table 1).

Table 1

Intra- and interobserver reproducibility statistics

\begin{tabular}{|c|c|c|c|c|c|c|}
\hline & \multicolumn{3}{|c|}{ Intra-observer reproducibility } & \multicolumn{3}{|c|}{ Inter-observer reproducibility } \\
\hline & $\begin{array}{l}\text { Mean } \\
\text { difference }\end{array}$ & $\begin{array}{l}\text { SD of } \\
\text { difference }\end{array}$ & ICC & $\begin{array}{l}\text { Mean } \\
\text { difference }\end{array}$ & $\begin{array}{l}\text { SD of } \\
\text { difference }\end{array}$ & ICC \\
\hline $\begin{array}{l}\text { apA-d } \\
\left({ }^{\circ}\right)\end{array}$ & 8.28 & 1.90 & 0.87 & 10.97 & 2.25 & 0.85 \\
\hline $\begin{array}{l}\text { apA-s } \\
\left(\left(^{\circ}\right)\right.\end{array}$ & 5.64 & 2.95 & 0.98 & 8.13 & 4.71 & 0.94 \\
\hline $\begin{array}{l}\text { Vap } \\
(\mathrm{m} / \mathrm{s})\end{array}$ & 0.03 & 0.02 & 0.99 & 0.04 & 0.03 & 0.99 \\
\hline
\end{tabular}

\section{Results}

Thirty suspected AHCM patients were identified, who showed TWI $\geq 0.05 \mathrm{mV}$ on precordial ECG and 4 of them had GNT. The patients with typical AHCM all had TWI and 34\% had GNT. None of the healthy and hypertensive control groups had TWI or GNT. None of the suspected AHCM patients had diameter stenosis $\geq 50 \%$ in coronary arteries by coronary angiography or computed tomography angiography. The maximal apical wall thickness of this group was $13.3 \pm 1.2 \mathrm{~mm}$, which was significantly higher than in normal controls $(6.0 \pm 0.6 \mathrm{~mm}, p<0.001)$, but none of them exceed $15 \mathrm{~mm}$. Nine suspected AHCM 
patients were symptomatic at the first presentation with mild symptoms of palpitations, dyspnea, dizziness, syncope, but without sustained symptomatic or ECG improvement to seek alternative diagnosis. The remaining 12 asymptomatic patients were present for further echocardiographic assessment because of incidental abnormal findings by ECG or routine echocardiography. Table 2 summarizes the general characteristics of the groups of the subjects in this study. Overall, there was no significant difference between patients with suspected AHCM and normal controls, except suspected AHCM patients had mildly reduced heart rate $(63 \pm 6$ vs. $67 \pm 9, p=0.042)$ and significantly higher systolic pressure $(134 \pm 20$ vs. $122 \pm 11 \mathrm{mmHg}, p=0.004)$ which still lower than patients with essential hypertension ( $145 \pm 20$ vs. $134 \pm 20 \mathrm{mmHg}, p=0.042$ ). There was no significant difference in blood pressure between the suspected and typical AHCM patients.

Table 2

Baseline characteristics of patients and control subjects (suspected patients versus the other groups)

\begin{tabular}{|c|c|c|c|c|c|c|c|}
\hline & $\begin{array}{l}\text { Suspected } \\
\text { patients } \\
(n=30)\end{array}$ & $\begin{array}{l}\text { AHCM } \\
(n=32)\end{array}$ & $\mathbf{P}$ & $\begin{array}{l}\text { Hypertension } \\
(n=44)\end{array}$ & $\mathbf{P}$ & $\begin{array}{l}\text { Normal } \\
\text { control } \\
(n=43)\end{array}$ & $\mathbf{P}$ \\
\hline Age & $59 \pm 11$ & $57 \pm 14$ & 0.687 & $59 \pm 11$ & 0.993 & $57 \pm 7$ & 0.553 \\
\hline Male n(\%) & $17(80.9 \%)$ & $23(71.9 \%)$ & 0.671 & $39(88.6 \%)$ & 0.649 & $35(81.4 \%)$ & 1.000 \\
\hline Height(cm) & $166.5 \pm 8.4$ & $\begin{array}{l}166.7 \pm \\
7.7\end{array}$ & 0.952 & $167.0 \pm 5.5$ & 0.796 & $\begin{array}{l}169.0 \pm \\
5.0\end{array}$ & 0.206 \\
\hline Weight(kg) & $65.0 \pm 10.0$ & $\begin{array}{l}69.3 \pm \\
11.9\end{array}$ & 0.171 & $65.9 \pm 9.7$ & 0.730 & $63.6 \pm 9.1$ & 0.602 \\
\hline $\mathrm{BSA}\left(\mathrm{m}^{2}\right)$ & $1.8 \pm 0.2$ & $1.8 \pm 0.2$ & 0.293 & $1.8 \pm 0.1$ & 0.688 & $1.8 \pm 0.1$ & 0.990 \\
\hline $\mathrm{SBP}(\mathrm{mmHg})$ & $134 \pm 20$ & $138 \pm 19$ & 0.460 & $145 \pm 20$ & 0.042 & $122 \pm 11$ & 0.004 \\
\hline $\mathrm{DBP}(\mathrm{mmHg})$ & $75 \pm 11$ & $79 \pm 12$ & 0.267 & $80 \pm 18$ & 0.191 & $76 \pm 9$ & 0.745 \\
\hline $\mathrm{HR}(\mathrm{bpm})$ & $63 \pm 6$ & $68 \pm 10$ & 0.036 & $69 \pm 9$ & 0.002 & $67 \pm 9$ & 0.042 \\
\hline TWI n(\%) & $30(100 \%)$ & $32(100 \%)$ & 0.111 & 0 & $\begin{array}{l}< \\
0.001\end{array}$ & 0 & $\begin{array}{l}< \\
0.001\end{array}$ \\
\hline GNT n(\%) & $4(19 \%)$ & $11(34 \%)$ & $<.001$ & 0 & $<.001$ & 0 & $\begin{array}{l}< \\
0.001\end{array}$ \\
\hline
\end{tabular}

Comparisons of conventional echocardiography between suspected AHCM patients and typical AHCM patients and normal/hypertensive controls (Table 3) 
Table 3

Parameters of conventional echocardiography (suspected patients versus the other groups)

\begin{tabular}{|c|c|c|c|c|c|c|c|}
\hline & $\begin{array}{l}\text { Suspected } \\
\text { patients } \\
(n=30)\end{array}$ & $\begin{array}{l}\text { AHCM } \\
(n=32)\end{array}$ & $\mathbf{P}$ & $\begin{array}{l}\text { Hypertension } \\
(n=44)\end{array}$ & $P$ & $\begin{array}{l}\text { Normal } \\
\text { control } \\
(n=43)\end{array}$ & $P$ \\
\hline IVST (mm) & $10.8 \pm 2.4$ & $\begin{array}{l}12.2 \pm \\
2.7\end{array}$ & 0.052 & $12.3 \pm 1.8$ & 0.014 & $7.8 \pm 1.0$ & $\begin{array}{l}< \\
0.001\end{array}$ \\
\hline LVPWT (mm) & $10.0 \pm 1.7$ & $\begin{array}{l}10.1 \pm \\
1.8\end{array}$ & 0.729 & $11.3 \pm 1.8$ & 0.004 & $8.1 \pm 1.0$ & $\begin{array}{l}< \\
0.001\end{array}$ \\
\hline LVEDV(ml) & $92.5 \pm 21.5$ & $\begin{array}{l}87.0 \pm \\
24.8\end{array}$ & 0.416 & $91.5 \pm 22.2$ & 0.862 & $\begin{array}{l}102.8 \pm \\
18.6\end{array}$ & 0.057 \\
\hline LVESV(ml) & $30.4 \pm 11.7$ & $\begin{array}{l}33.9 \pm \\
8.9\end{array}$ & 0.264 & $32.0 \pm 9.0$ & 0.570 & $\begin{array}{l}40.3 \pm \\
11.0\end{array}$ & 0.002 \\
\hline $\mathrm{SV}(\mathrm{ml})$ & $62.1 \pm 16.9$ & $\begin{array}{l}55.9 \pm \\
13.2\end{array}$ & 0.149 & $59.5 \pm 15.4$ & 0.551 & $\begin{array}{l}62.5 \pm \\
10.4\end{array}$ & 0.922 \\
\hline LVEF(\%) & $67 \pm 9$ & $62 \pm 6$ & 0.024 & $65 \pm 5$ & 0.249 & $61 \pm 5$ & 0.002 \\
\hline LAV(ml) & $66.9 \pm 25.5$ & $\begin{array}{l}76.9 \pm \\
15.8\end{array}$ & 0.121 & $47.9 \pm 14.0$ & 0.004 & $\begin{array}{l}43.4 \pm \\
14.2\end{array}$ & 0.001 \\
\hline $\mathrm{LAVI}\left(\mathrm{ml} / \mathrm{cm}^{2}\right)$ & $37.4 \pm 14.3$ & $\begin{array}{l}43.6 \pm \\
9.8\end{array}$ & 0.071 & $26.0 \pm 7.3$ & 0.002 & $\begin{array}{l}23.71 \pm \\
7.49\end{array}$ & $\begin{array}{l}< \\
0.001\end{array}$ \\
\hline $\mathrm{A}(\mathrm{m} / \mathrm{s})$ & $0.69 \pm 0.15$ & $\begin{array}{l}0.68 \pm \\
0.16\end{array}$ & 0.935 & $0.83 \pm 0.21$ & 0.008 & $\begin{array}{l}0.68 \pm \\
0.13\end{array}$ & 0.839 \\
\hline $\mathrm{E}(\mathrm{m} / \mathrm{s})$ & $0.73 \pm 0.18$ & $\begin{array}{l}0.68 \pm \\
0.19\end{array}$ & 0.391 & $0.69 \pm 0.20$ & 0.441 & $\begin{array}{l}0.70 \pm \\
0.16\end{array}$ & 0.496 \\
\hline E/A ratio & $1.06 \pm 0.26$ & $\begin{array}{l}1.08 \pm \\
0.56\end{array}$ & 0.896 & $0.87 \pm 0.29$ & 0.015 & $\begin{array}{l}0.98 \pm \\
0.35\end{array}$ & 0.401 \\
\hline $\begin{array}{l}\mathrm{e}_{1} \text { (lateral) } \\
(\mathrm{m} / \mathrm{s})\end{array}$ & $0.09 \pm 0.03$ & $\begin{array}{l}0.08 \pm \\
0.03\end{array}$ & 0.208 & $0.09 \pm 0.03$ & 0.914 & $\begin{array}{l}0.11 \pm \\
0.03\end{array}$ & 0.012 \\
\hline $\begin{array}{l}e_{2} \text { (septal) } \\
(\mathrm{m} / \mathrm{s})\end{array}$ & $0.06 \pm 0.02$ & $\begin{array}{l}0.05 \pm \\
0.01\end{array}$ & 0.065 & $0.06 \pm 0.02$ & 0.130 & $\begin{array}{l}0.08 \pm \\
0.02\end{array}$ & $\begin{array}{l}<.001 \\
0.001\end{array}$ \\
\hline E/e' ratio & $11.0 \pm 5.0$ & $\begin{array}{l}11.3 \pm \\
3.7\end{array}$ & 0.109 & $9.6 \pm 3.7$ & 0.221 & $7.7 \pm 2.0$ & 0.007 \\
\hline \multicolumn{8}{|c|}{$\begin{array}{l}\text { e': average of } e_{1} \text { and } e_{2} ; e_{1} \text { (lateral): tissue Doppler early diastolic wave at basal ventricular septum; } \\
e_{2}(\text { septal): tissue Doppler early diastolic wave at basal LV lateral wall; IVST: interventricular septum } \\
\text { thickness; LAV: left atrial volume; LAVI: left atrial volume index; LVDd: left ventricular end-diastolic } \\
\text { dimension; LVDs: left ventricular end-systolic dimension; LVEDV: left ventricular end-diastolic volume; } \\
\text { LVEF: left ventricular ejection fraction; LVESV: left ventricular end-systolic volume; LVPWT: left } \\
\text { ventricular posterior wall thickness; A: pulse Doppler mitral valve A wave; E: pulse Doppler mitral valve } \\
\text { E wave; SV: stroke volume }\end{array}$} \\
\hline
\end{tabular}


The myocardium at LV basal was thicker in suspected AHCM patients than in normal controls. Compared to normal controls, suspected AHCM patients had normal LV size with significantly increased LVEF, E/e' ratio and LA volume index.

In patients with typical AHCM, there was a similar LV basal wall thickness as suspected AHCM patients. There was no significant difference in LV diastolic performance between the two groups of AHCM patients. Compared to the suspected AHCM patients, hypertensive patients had significantly, thicker LV basal wall, comparable LVEF, and smaller LAVI.

Comparisons of apical morphological and dynamic characteristics between suspected AHCM patients and typical AHCM patients and normal/hypertensive controls (Table 4) 
Table 4

The apical morphological and dynamic parameters measured by echocardiography (suspected patients versus the other groups)

\begin{tabular}{|c|c|c|c|c|c|c|c|}
\hline & $\begin{array}{l}\text { Suspected } \\
\text { patients } \\
(n=30)\end{array}$ & $\begin{array}{l}\text { AHCM } \\
(n=32)\end{array}$ & $\mathbf{P}$ & $\begin{array}{l}\text { Hypertension } \\
(n=44)\end{array}$ & $\mathbf{P}$ & $\begin{array}{l}\text { Normal } \\
\text { control } \\
(n= \\
43)\end{array}$ & $\mathbf{P}$ \\
\hline $\mathrm{APWT}_{\max }$ & $13.3 \pm 1.2$ & $18.2 \pm 1.7$ & $\begin{array}{l}< \\
0.001\end{array}$ & $8.4 \pm 1.3$ & $<.001$ & $\begin{array}{l}6.0 \pm \\
0.6\end{array}$ & $\begin{array}{l}< \\
0.001\end{array}$ \\
\hline ABR & $1.37 \pm 0.23$ & $\begin{array}{l}1.85 \pm \\
0.42\end{array}$ & $<.001$ & $0.75 \pm 0.11$ & $\begin{array}{l}< \\
0.001\end{array}$ & $\begin{array}{l}0.75 \pm \\
0.08\end{array}$ & $\begin{array}{l}<.001 \\
0.001\end{array}$ \\
\hline apA-d $\left(^{\circ}\right)$ & $85.9 \pm 22.6$ & $\begin{array}{l}79.0 \pm \\
12.2\end{array}$ & 0.107 & $96.7 \pm 11.0$ & 0.047 & $\begin{array}{l}103.3 \\
\pm 6.2\end{array}$ & 0.002 \\
\hline $\operatorname{apA}-\mathrm{s}\left({ }^{\circ}\right)$ & $23.7 \pm 21.3$ & $\begin{array}{l}16.9 \pm \\
28.6\end{array}$ & 0.367 & $69.5 \pm 14.1$ & $\begin{array}{l}<.001 \\
0.001\end{array}$ & $\begin{array}{l}86.9 \pm \\
9.0\end{array}$ & $\begin{array}{l}<.001 \\
0.001\end{array}$ \\
\hline$\triangle \mathrm{apA}(\%)$ & $74 \pm 23$ & $80 \pm 33$ & 0.490 & $28 \pm 13$ & $<0.001$ & $16 \pm 8$ & $\dot{0.001}$ \\
\hline $\begin{array}{l}\text { Cavity } \\
\text { obliteration } \\
\mathrm{n}(\%)\end{array}$ & $6(28.6 \%)$ & $21(65.6 \%)$ & $\begin{array}{l}< \\
0.001\end{array}$ & 0 & $\begin{array}{l}<.001 \\
0.001\end{array}$ & 0 & $\begin{array}{l}<.001 \\
0.00\end{array}$ \\
\hline $\operatorname{Vap}(\mathrm{m} / \mathrm{s})$ & $0.49 \pm 0.25$ & $\begin{array}{l}0.88 \pm \\
0.50\end{array}$ & 0.001 & $0.32 \pm 0.11$ & 0.006 & $\begin{array}{l}0.24 \pm \\
0.06\end{array}$ & $\hat{0}_{0.001}$ \\
\hline $\mathrm{V}_{\mathrm{LVOT}}(\mathrm{m} / \mathrm{s})$ & $1.07 \pm 0.22$ & $\begin{array}{l}1.17 \pm \\
0.24\end{array}$ & 0.155 & $1.04 \pm 0.16$ & 0.502 & $\begin{array}{l}0.91 \pm \\
0.15\end{array}$ & 0.004 \\
\hline Vap $/ \mathrm{V}_{\mathrm{LVOT}}$ ratio & $0.5 \pm 0.3$ & $0.8 \pm 0.5$ & 0.009 & $0.3 \pm 0.1$ & 0.017 & $\begin{array}{l}0.3 \pm \\
0.1\end{array}$ & 0.003 \\
\hline $\begin{array}{l}\text { ABR: apical bas } \\
\text { systole; APWT } \\
\text { at apex; } V_{\text {LVOT: }} p\end{array}$ & $\begin{array}{l}\text { vall thicknes } \\
\text { maximal ap }\end{array}$ & $\begin{array}{l}\text { o; apA-d: a } \\
\text { all thickne }\end{array}$ & $\begin{array}{l}\text { al ang } \\
\text { TWl: }\end{array}$ & $\begin{array}{l}\text { t end-diastole } \\
\text { ave inversion; } \\
\text { fllow tract }\end{array}$ & $\begin{array}{l}\text { A-s: } \\
\text { p: pu }\end{array}$ & $\begin{array}{l}\text { cal angl } \\
\text { Dopple }\end{array}$ & $\begin{array}{l}\text { tend- } \\
\text { elocity }\end{array}$ \\
\hline
\end{tabular}

Compared to normal controls, suspected AHCM patients had significantly higher ABR, lower apical angles and higher percentage change of the apical angle. The Doppler velocity at LV apex and velocity ratio were significantly higher in suspected AHCM compared to normal controls. There was no significant difference in apical angles or its percentage change during the cardiac cycle between patients with typical AHCM and patients with suspected AHCM. ABR was significantly higher in typical AHCM patients than in suspected AHCM patients. The Doppler velocity at LV apex and velocity ratio in patients with AHCM was significantly higher than in patients with suspected AHCM. Compared to patients with suspected AHCM, hypertensive patients had significantly wider apical angles, less dynamic change of the apical angle during cardiac cycle, and lower ABR and velocity ratio. 
There was no significant difference between hypertension and healthy controls in the mean ABR $(0.75 \pm$ 0.11 vs $0.75 \pm 0.08, P \llbracket 0.05$ ) while the mean basal wall thickness was greater in hypertension than healthy control group $(12.3 \pm 1.8 \mathrm{~mm}$ vs $7.8 \pm 1.0 \mathrm{~mm}, \mathrm{P}<0.001)$.

\section{Discussion}

\section{Suspected AHCM is likely a mild form of AHCM}

In the current study we found 30 patients with TWI and mild apical hypertrophy that did not meet the diagnostic criteria of AHCM. These patients, however, shared similar apical morphology and dynamic characteristics as typical AHCM. This suspected AHCM group had four important features: (1) unexplainable deep T-wave inversion observed mostly in the V3-V5 leads; (2) relative apical hypertrophy (ABR more than 1); (3) reduced apical angles and a high percentage change of the apical angle; and (4) increased Vap and velocity ratio. A previous MRI study also reported reduced apical angle in this nontypical AHCM group ${ }^{5}$. The decreased apical angle can be caused by mildly thickened apical myocardium, suggesting that the apA metric can be used to assess the apical morphological changes in the early stages.

We firstly used apical blood flow velocity and found both suspected and typical AHCM patients had significantly accelerated apical flow than the controls. The high apical velocity can be a result of increased myocardial contractility, caused by increased heart rate and/or systemic hypertension. The hypertensive group in the current study, although with higher heart rate and higher blood pressure than the suspected AHCM group, appeared to have a lower apical flow velocity. This indicates that other mechanisms, such as gene mutations in $\mathrm{HCM}$, result in hypercontractility of the cardiac muscle 10,11 . Another possible explanation for the accelerated apical flow is the lower apical volume in systole caused by the thickened apical myocardium in both suspected and typical AHCM groups. Both the apical morphology and dynamic characteristics observed by echocardiography point to a pathological apex in suspected AHCM patients. Some researchers believe that this cohort may suffer from a morphologically mild form or subtype of $\mathrm{AHCM}$ and share the same prognosis as $\mathrm{AHCM}^{4}$. Our echocardiographic findings support this opinion.

\section{Abnormal Ecg In Patients With Suspected Ahcm}

The presence of deep TWI in the precordial ECG leads indicate abnormalities in the myocardium repolarization, which can occur in various conditions. Common identifiable etiologies for TWI, such as myocardial ischemia, central nervous system injury, pulmonary embolism or electrolyte imbalance were excluded in this study. The morphological changes of the apex were therefore the most likely explanation for TWI. Although a deeper T-wave inversion in the V3-V5 leads alone is not sufficient for diagnosing AHCM, ECG is certainly a useful screening tool ${ }^{12,13}$. In patients with TWI, the evidence of abnormal apical 
morphology and dynamic characteristics from a regular echocardiographic exam can further support the diagnosis and help to detect the group with mild form of AHCM.

\section{Diagnostic Value Of Echocardiography For Detecting Ahcm}

Wu et al. reported that the decrease in the apical angle and abnormal wall thickness gradient by CMR are sensitive markers that reflect early apical morphological changes in $\mathrm{AHCM}^{5}$. We believe that by optimizing the image quality, these markers can be assessed using echocardiography in a good amount of patients. In the current study, using focused B-mode imaging and a high-frequency probe, we were able to locate a group of patients with mild apical hypertrophy that shared apical morphological and dynamic characteristics as typical AHCM patients. Echocardiography has been criticized for false negative findings in patients with $\mathrm{AHCM}^{14}$, however, by including additional quantitative measurements as we have adopted in the current study, such as ABR, apical angle and apical velocity, the diagnostic value of echocardiography can be significantly improved. Further studies with larger sample sizes and involving multiple modalities would be needed to confirm the role of additional quantification by echocardiography in diagnosing AHCM.

\section{Suspected Ahcm Vs. Hypertension}

As most patients in both typical and suspected AHCM groups in this study also suffer from hypertension, it is important to rule out the impact of this comorbidity on the apical morphology and dynamics. We found that no hypertensive individual in the control group had TWI or an ABR $>0.95$, which is similar to the findings by Flett et $\mathrm{al}^{4}$. Increased LV afterload by high blood pressure commonly leads to concentric LV hypertrophy which is characterized by uniformly increased LV wall thickness. However, significant role

of genetics is suggested in the pathogenesis of AHCM, which may well target the apical region. ${ }^{15}$ From our results, we found mild or no change in the apical angles and velocity ratio in hypertensive control patients compared to healthy controls. Both AHCM and suspected AHCM groups however had significantly decreased apical angles and significantly increased apical flow velocity and velocity ratio. Furthermore, apical obliteration was observed in approximately $30 \%$ suspected AHCM patients and $60 \%$ AHCM patients, but not in the hypertensive or healthy controls. These additional characteristics by echocardiography help to reveal the difference between pathologies.

\section{Limitations}

In patients with poor acoustic windows and poor image quality, the quantitative methods introduced in current paper for assessment of apical morphology and dynamics had certainly limitations. More sophisticated methods for LV apex detection, such as using ultrasound enhancing agent or magnetic resonance imaging, would be indicated. Although the results from current study supports the existence of a group of patients with mild AHCM, we still don't know the clinical outcome of this group. Future 
longitudinal study is certainly needed. Genetic testing was not routinely performed in this study. Nor the 2D strains of LV were investigated. It will be interesting to study if the mild AHCM also share the same gene mutations as $\mathrm{AHCM}^{16}$ and has the same reduction of regional function ${ }^{17}$. Finally, this is a study with a relatively small sample size from a single center. Further research in a larger patient cohort involving multi-center and multiple imaging modalities will be needed to clarify the diagnostic value of the additional echocardiographic quantification in identifying patients with mild AHCM or AHCM in its early stage.

\section{Conclusion}

We identified a group of patients with an unexplainable deep T-wave inversion on their ECG and mild apical hypertrophy (apical wall thickness $<15 \mathrm{~mm}$ ). The additional echocardiographic features of this group included increased apical to basal thickness ratio, decreased apical angle and increased apical blood flow velocity ratio compared to healthy and hypertensive controls which share the similarity as typical AHCM and distinguish the group from normal and hypertensive controls. Our results support the idea that the suspected AHCM group is an early or mild phenotype of AHCM. The presence of more features may be more supportive. Careful echocardiographic examination and additional quantitative measurements may be beneficial for clinicians to identify such individuals and appropriately arrange a follow-up, family screening or genetic testing.

\section{Abbreviations}

AHCM:apical hypertrophic cardiomyopathy; apA:apical angle; Vap:apical velocity; TWI:T wave inverse; GNT:giant negative T-wave; APWT max:maximal apical wall thickness; ABR:apex:base ratio; LV:left ventricle; LVOT:left ventricular outflow tract; IVST:interventricular septum thickness; LVPWT:left ventricular basal posterior wall thickness; LVEF:left ventricular ejection fraction; LAV:left atrium volume; CMR:cardiac magnetic resonance.

\section{Declarations}

\section{Acknowledgements}

Not applicable

\section{Funding}

This study was supported by Medical Innovation Project from Fujian Provincial Health and Family Planning Commission in China [2016-CX-35] and Major Guidance Project for Social Development from Fujian Provincial Department of Science and Technology in China [2017Y0031].

\section{Availability of data and materials}


The data and material in the current study are available from the corresponding author on reasonable request.

\section{Authors' contributions}

Shengnan Lin carried out image acquisition and analysis, participated in the design of the study, drafted the manuscript, and performed statistical analysis. Qinyun Ruan conceived and designed the study, and revised the manuscript. Chunyan Huang participated in the design of the study and data collection. Lei Yan, Liyun Fu and Huang'e Cai participated in data collection. All authors read and approved the final manuscript.

\section{Ethics approval and consent to participate}

The study was approved by the Ethics Committee of the First Affiliated Hospital of Fujian Medical University \{NO\&[2015]127\}.

\section{Consent for publication}

Not applicable

\section{Competing interests}

The authors declare that they have no competing interests.

\section{References}

1. Jan MF, Todaro MC, Oreto L, Tajik AJ. Apical hypertrophic cardiomyopathy: Present status. Int J Cardiol. 2016;222:745-59.

2. Gruner C, Care M, Siminovitch K, Moravsky G, Wigle DE, Woo A, Rakowski H. Sarcomere protein gene mutations in patients with apical hypertrophic cardiomyopathy. Circ Cardiovasc Genet. 2011;CIRCGENETICS-110.

3. Elliott PM, Anastasakis A, Borger MA, Borggrefe M, Cecchi F, Charron P et al. 2014 ESC Guidelines on diagnosis and management of hypertrophic cardiomyopathy: the Task Force for the Diagnosis and Management of Hypertrophic Cardiomyopathy of the European Society of Cardiology (ESC). Eur Heart J. 2014;35:2733-99.

4. Flett AS, Maestrini V, Milliken D, Fontana M, Treibel TA. Diagnosis of apical hypertrophic cardiomyopathy: T-wave inversion and relative but not absolute apical left ventricular hypertrophy. Int J Cardiol. 2015;183:143-8.

5. Wu B, Lu M, Zhang Y, Song B, Ling J, Huang J et al. CMR assessment of the left ventricle apical morphology in subjects with unexplainable giant T-wave inversion and without apical wall thickness $\geq 15$ mm. Eur HeartJ Cardiovasc Imaging. 2017;18:186-94. 
6. Chun EJ, Choi SI, Jin KN, Kwag HJ, Kim YJ, Choi BW et al. Hypertrophic cardiomyopathy: assessment with MR imaging and multidetector CT. Radiographics. 2010; 30: 1309-28.

7. Ward RP, Weinert L, Spencer KT, Furlong KT, Bednarz J, DeCara J, Lang RM. Quantitative diagnosis of apical cardiomyopathy using contrast echocardiography. J Am Soc Echocardiogr. 2002;15:316-22.

8. Eriksson MJ, Sonnenberg B,Woo A, Rakowski P, Parker TG, Wigle ED et al. Long-term outcome in patients with apical hypertrophic cardiomyopathy. J Am Coll Cardiol. 2002;39:638-45.

9. Lang RM, Badano, LP, Mor-Avi V, Afilalo J, Armstrong A, Ernande, L et al. Recommendations for cardiac chamber quantification by echocardiography in adults: an update from the American Society of Echocardiography and the European Association of Cardiovascular Imaging. Eur Heart $\mathrm{J}$ Cardiovasc Imaging. 2015;16:233-71.

10. Spudich JA. The myosin mesa and a possible unifying hypothesis for the molecular basis of human hypertrophic cardiomyopathy. Biochem Soc Trans. 2015; 43: 64-72.

11. Olivotto I. Contractile persistence in apical hypertrophic cardiomyopathy: Definitely too much of a good thing. Int J Cardiol. 2018; 251: 71-73.

12. Caselli S, Pelliccia A.The electrocardiogram and the phenotypic expression of hypertrophic cardiomyopathy. Eur Heart J. 2019; 40: 982-5.

13. Lyon A, Bueno-Orovio A, Zacur E, Ariga R, Grau V, Neubauer S et al. Electrocardiogram phenotypes in hypertrophic cardiomyopathy caused by distinct mechanisms: apico-basal repolarization gradients vs. Purkinje-myocardial coupling abnormalities. Europace. 2018; 20: iii102-iii12.

14. Moon JC, Fisher NG, McKenna WJ, Pennell DJ. Detection of apical hypertrophic cardiomyopathy by cardiovascular magnetic resonance in subjects with nondiagnostic echocardiography. Heart. 2004; 90: 645-9.

15. Akhtar M, Elliott P. The genetics of hypertrophic cardiomyopathy. Glob Cardiol Sci Pract. 2018; 2018: 36.

16. Arad M, Penas-Lado M, Monserrat L, Maron BJ, Sherrid M, Ho CY et al. Gene mutations in apical hypertrophic cardiomyopathy. Circulation. 2005;112:2805-11.

17. Saccheri MC, Cianciulli TF, Morita LA, Méndez RJ, Beck MA, Guerra JE et al: Speckle tracking echocardiography to assess regional ventricular function in patients with apical hypertrophic cardiomyopathy. World journal of cardiology. 2017; 9: 363.

\section{Figures}



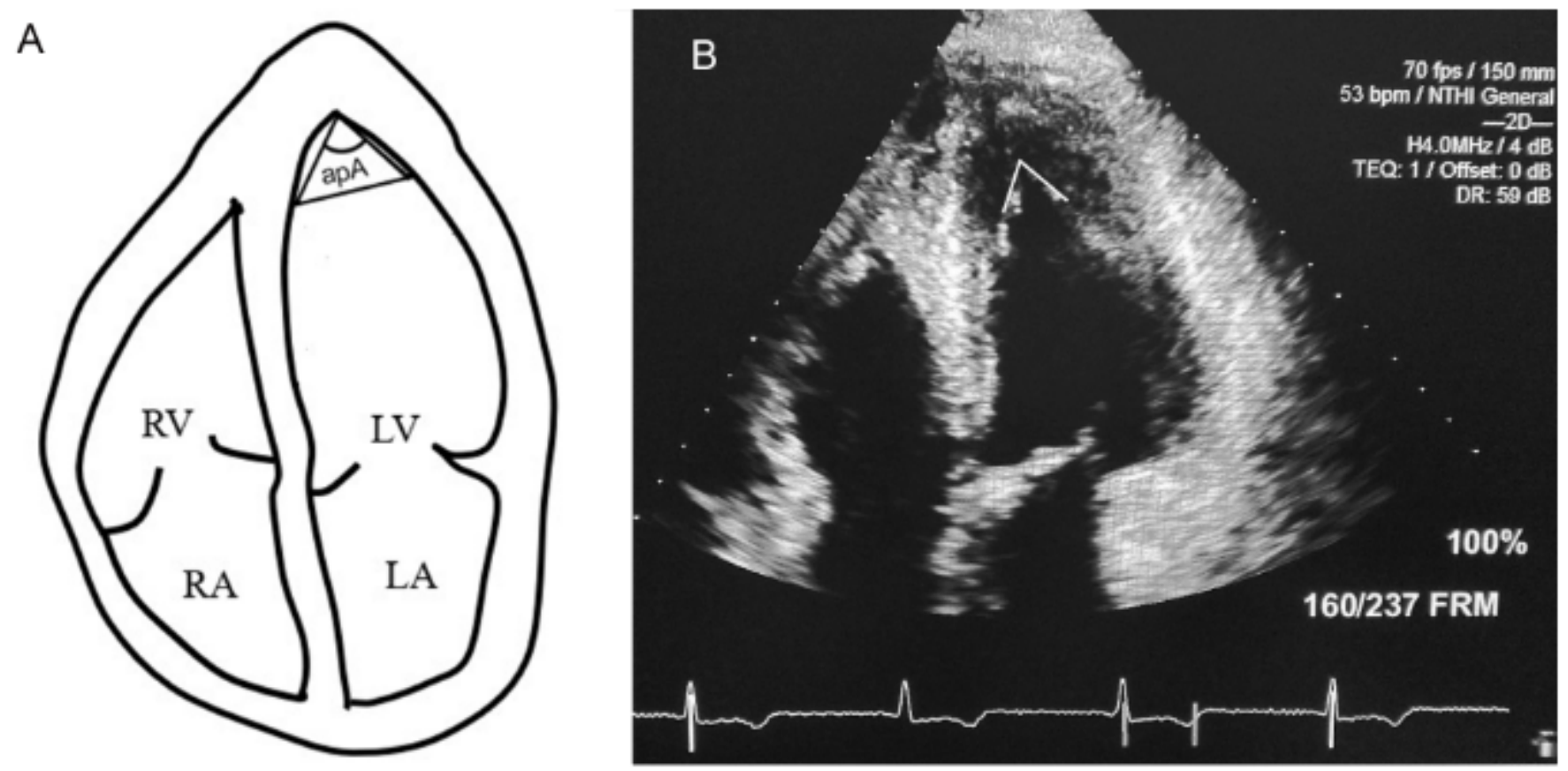

Figure 1

Schematic diagram (A) and echocardiopraphic image (B). In the apical four chamber view, two lines were drawn from the endocardial apex to the two points of the endocardium at 1/6 of the long axis length of the LV. The angle between the two additional lines was defined as the apical angle (apA). LA: left atrium; LV: left ventricle; RA: right atrium; RV: right ventricle.

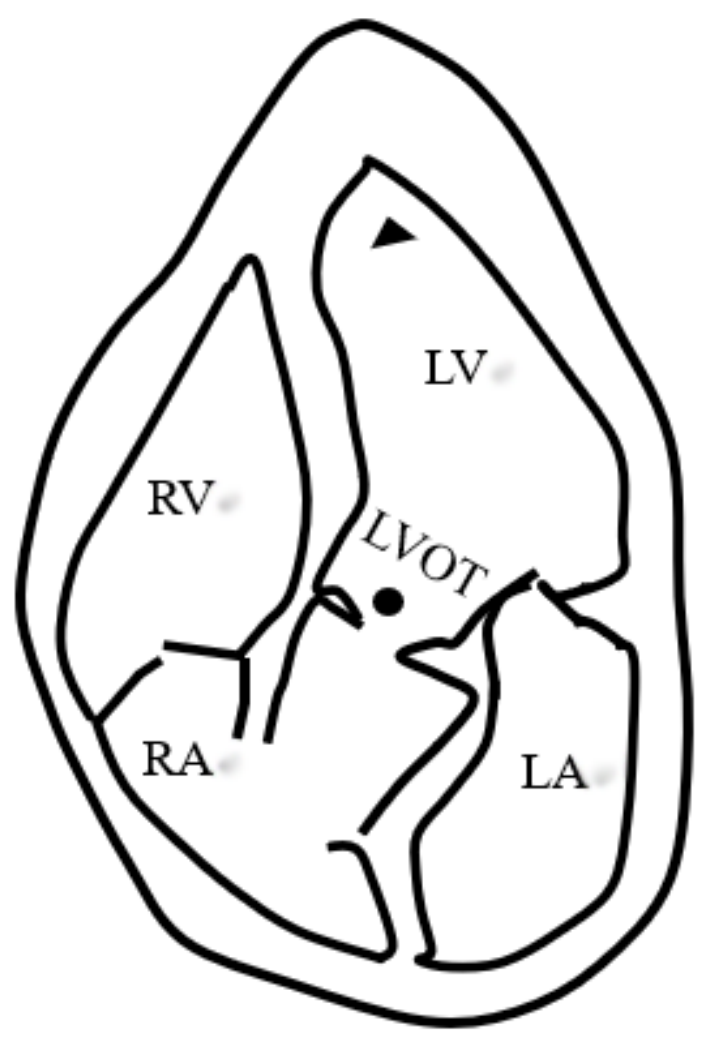




\section{Figure 3}

Schematic diagram of the apical five-chamber view. Pulse Doppler velocities were measured at the LV apex (, at $1 / 6$ of the LV long axis) and the LVOT (, just underneath the aortic annulus). LV: left ventricle, LVOT: left ventricular outflow tract.

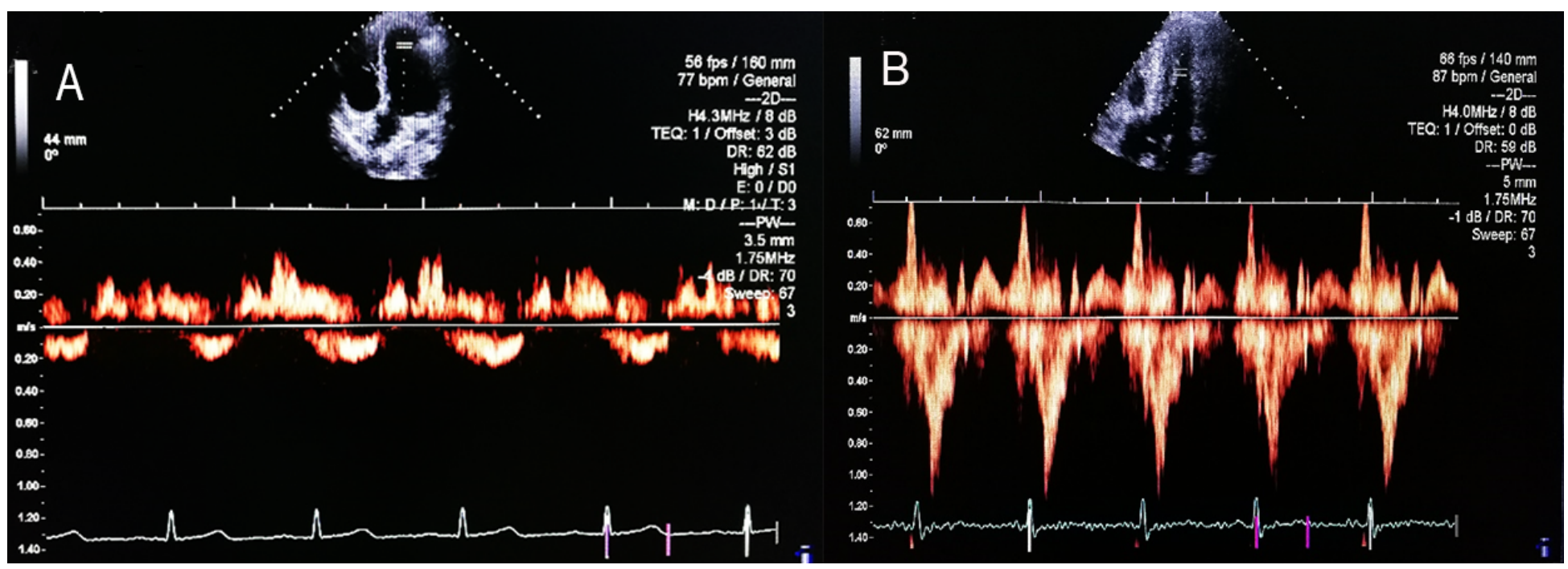

\section{Figure 5}

The velocity of the apical cavity (Vap) (under the baseline) in AHCM (B) was significantly higher than that in a normal control $(A)$. 